\title{
Mending cracks in the nuclear establishment
}

\author{
Alvin M. Weinberg
}

SIR Alan Cottrell has written a wellbalanced, popular account of the issues around which the nuclear energy debate swirls: reactor safety, waste disposal, proliferation, terrorism and the political implications of nuclear energy. He ignores costs, availability of uranium and the need for electricity, for "in the end it is [safety], not any of these other factors, which will eventually decide the acceptability of nuclear power in Western democratic society". I agree with Sir Alan's assessment, though the bombing of the Iraqi reactor at Tamuz could give to the proliferation issue more political force than it now has.

Sir Alan is strongly pro-nuclear, but this does not prevent him from focusing upon his concerns about reactor safety. Though he believes that reactors can in principle be made safe enough, he does not say whether they will be made safe enough. For Sir Alan, not all reactors are equally safe: brittle fracture of the pressure vessel in a light water reactor remains its Achilles heel, despite the more optimistic conclusions of the 1976 inquiry, led by Walter Marshall, into the integrity of light water pressure vessels. The Marshall Report insisted that such vessels were safe, especially since cracks large enough to be threatening could be detected by ultrasonic probes with more than 95 per cent probability.

Ninety-five per cent reliability is surely a difficult - some would say impossible goal. Sir Alan invokes the somewhat controversial 1979 OECD report to conclude that only one-half, rather than 95 per cent, of all serious cracks can be detected: "an improvement is needed . . . up at least to the Marshall figure". Without quite saying so, Sir Alan still seems to be sceptical of light water reactors.

Yet his position is not impregnable. In requiring a 95 per cent instead of 50 per cent detection probability, he in effect accepts a brittle failure probability of $10^{-7}$ per year, but rejects a probability of $10^{-6}$ per year. Such fine tuning seems to me artificial. More realistic than such precise computation of extremely unlikely events is the assurance that the failure of a pressure vessel is all but impossible: both $10^{-6}$ and $10^{-7}$ per year are "all but impossible"'.

Sir Alan's criterion of acceptability follows from a too literal application of
How Safe is Nuclear Energy? By Alan Cottrell. Pp.124. ISBN 0-435-54175-7. (Heinemann Educational: 1981.) £2.50, \$6.

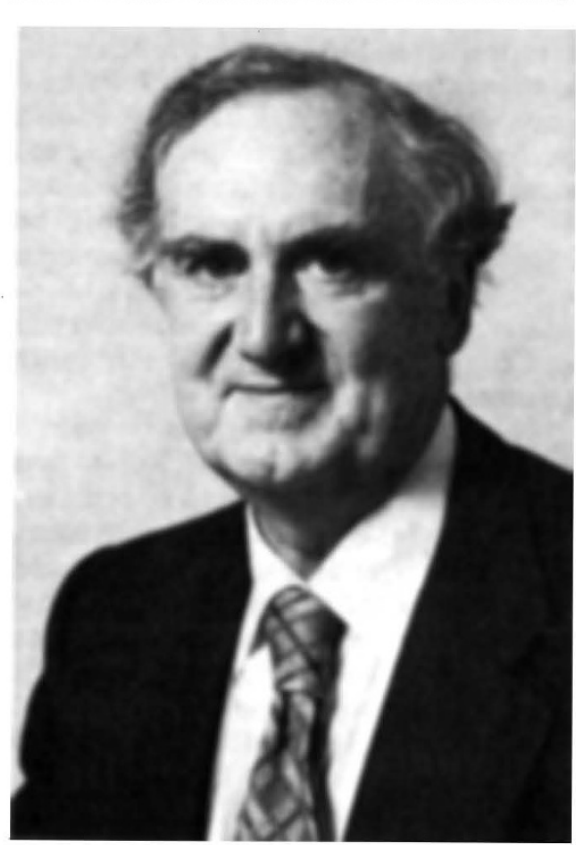

Sir Alan Cottrell - his concern about the embrittlement of pressure vessels is open to question but nonetheless should be taken seriously.

Farmer's recommendation of a safety standard:

(curies released in an accident) $\times$ (probability of accident) $<1$.

But how many curies might be released in an accident is by no means as clear as Sir Alan assumes. At Three Mile Island about $15 \mathrm{Ci}$, that is, less than $10^{-6}$ of the inventory, was actually released. Apparently, in the presence of water the iodine remains in solution rather than becoming airborne. This is an inherent safety advantage of the light water reactor, though whether one can count on the mechanism in the event of a catastrophic pressure vessel failure is debatable. Should these estimates prove correct, water-cooled reactors would pose at the very worst a much smaller risk to the public than Sir Alan estimates.

Yet neither can Sir Alan's concerns be ignored. The US Nuclear Regulatory Commission (NRC) has ordered that 14 of the older light water reactors be re-analysed to determine whether radiation has so embrittled the pressure vessels as to constitute a significant hazard in the event of an emergency injection of cold water. The action of the NRC demonstrates that the issue of pressure vessel embrittlement will not go away easily, even if one disagrees with Sir Alan's specific, and somewhat rigid, criterion of acceptability.

Are some reactor types inherently more "forgiving" than others? Until the United Kingdom debate on light water reactors versus advanced gas-cooled reactors, and before Three Mile Island, this question was hardly raised: all reactors were equally safe, if not by their nature, then by their design. The current widespread nuclear moratorium on new reactors might be a time to re-examine the relative forgiveness of different reactor types.

It is not a foregone conclusion that gascooled reactors will win in this competition. Copper-free steels that are much less subject to radiation embrittlement than were the older, less pure materials, now go into pressure vessels for newer light water reactors. This, together with the small release of iodine from water reactors (provided some liquid water remains after an accident), could balance the advantages of high heat capacity, low power density and pre-stressed concrete pressure envelopes of gas-cooled reactors.

When in 1946 the Oak Ridge group persuaded the then Captain Rickover to adopt pressurized water for Nautilus, radiation embrittlement of pressure vessels was not recognized as a concern. It is therefore not too surprising that 35 years later the issue of pressure vessel embrittlement has come alive. To be sure, the newer steels, plus the better inspection techniques and the lower iodine release fraction, taken together ought to allay Sir Alan's as well as the public's concern. But I hope we use the pause in deployment of reactors, especially in the United States, to ask whether the line of development we launched upon 35 years ago is still the path we ought to be following in a second nuclear era. Though Sir Alan's book will annoy both anti-nukes and most of the nuclear establishment (which is committed to light water reactors), his concerns about fracture of pressure vessels must be taken seriously.

Alvin M. Weinberg was formerly Director of the Oak Ridge National Laboratory, Oak Ridge, Tennessee. In 1946, together with F. H. Murray, he proposed the adoption of the pressurized water reactor. 